NATL INST. OF STAND \& TECH R.1.C.

A I11904 589844

Computer

Systems

Technology

U.S. DEPARTMENT OF COMMERCE

Technology Administration

National Institute of

Standards and Technology

\section{NLT}

\title{
Self Monitoring Accounting Systems
}

Roger Sies

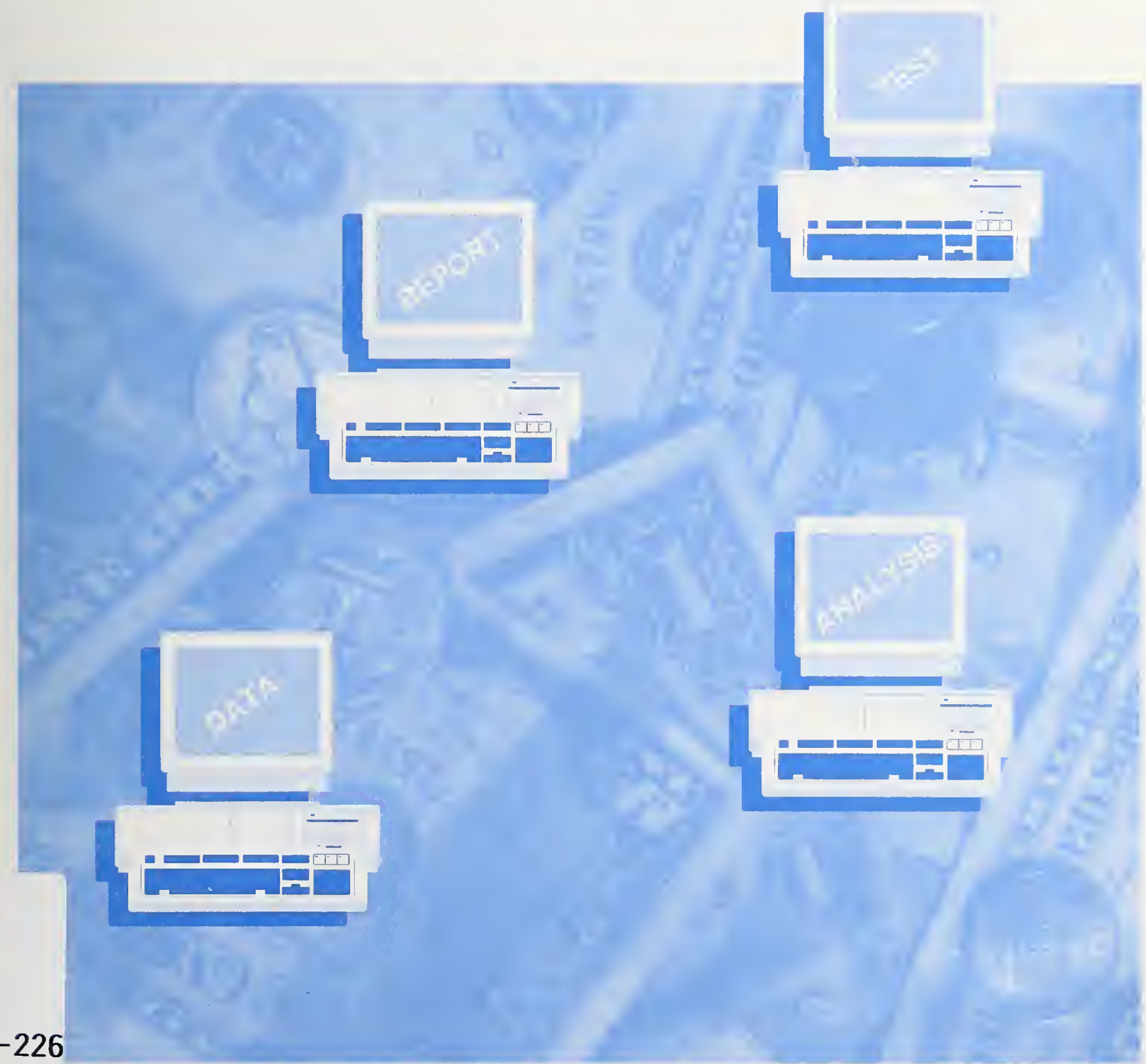

NO. 500-226 

in the development of teclinology ... needed to improve product quality, to modernize manufacturing processes. to ensure product reliability ... and to facilitate rapid commercialization ... of products based on new scientific discoveries."

NIST, originally founded as the National Bureau of Standards in 1901, works to strengthen U.S. industry's competitiveness; advance science and engineering; and improve public health, safety, and the environment. One of the agency's basic functions is to develop, maintain, and retain custody of the national standards of measurement, and provide the means and methods for comparing standards used in science, engineering, manufacturing, commerce, industry, and education with the standards adopted or recognized by the Federal Government.

As an agency of the U.S. Commerce Department's Technology Administration, NIST conducts basic and applied research in the physical sciences and engineering, and develops measurement techniques, test methods, standards, and related services. The Institute does generic and precompetitive work on new and advanced technologies. NIST's research facilities are located at Gaithersburg, MD 20899, and at Boulder. CO 80303. Major technical operating units and their principal activities are listed below. For more information contact the Public Inquiries Desk, 301-975-3058.

\section{Office of the Director}

- Advanced Technology Program

- Quality Programs

- International and Academic Affairs

\section{Technology Services}

- Manufacturing Extension Partnership

- Standards Services

- Technology Commercialization

- Measurement Services

- Technology Evaluation and Assessment

- Information Services

\section{Materials Science and Engineering}

Laboratory

- Intelligent Processing of Materials

- Ceramics

- Materials Reliability

- Polymers

- Metallurgy

- Reactor Radiation

\section{Chemical Science and Technology Laboratory \\ - Biotechnology \\ - Chemical Kinetics and Thermodynamics \\ - Analytical Chemical Research \\ - Process Measurements ${ }^{2}$ \\ - Surface and Microanalysis Science \\ - Thermophysics ${ }^{2}$}

\section{Physics Laboratory}

- Electron and Optical Physics

- Atomic Physics

- Molecular Physics

- Radiometric Physics

- Quantum Metrology

- Ionizing Radiation

- Time and Frequency ${ }^{\mathrm{l}}$

- Quantum Physics ${ }^{1}$

\section{Manufacturing Engineering Laboratory}

- Precision Engineering

- Automated Production Technology

- Intelligent Systems

- Manufacturing Systems Integration

- Fabrication Technology

\section{Electronics and Electrical Engineering} Laboratory

- Microelectronics

- Law Enforcement Standards

- Electricity

- Semiconductor Electronics

- Electromagnetic Fields'

- Electromagnetic Technology

- Optoelectronics

Building and Fire Research Laboratory

- Structures

- Building Materials

- Building Environment

- Fire Safety

- Fire Science

\section{Computer Systems Laboratory}

- Office of Enterprise Integration

- Information Systems Engineering

- Systems and Software Technology

- Computer Security

- Systems and Network Architecture

- Advanced Systems

\section{Computing and Applied Mathematics} Laboratory

- Applied and Computational Mathematics ${ }^{2}$

- Statistical Engineering²

- Scientific Computing Environments

- Computer Services

- Computer Systems and Communications ${ }^{2}$

- Information Systems

'At Boulder, CO 80303.

${ }^{2}$ Some elements at Boulder, CO 80303. 


\section{Self Monitoring Accounting Systems}

Roger F. Sies, Certified Internal Auditor

Computer Systems Laboratory

National Institute of Standards and Technology

Gaithersburg, MD 20899-0001

March 1995

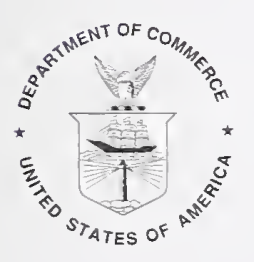

U.S. Department of Commerce

Ronald H. Brown, Secretary

Technology Administration

Mary L. Good. Under Secretary for Technology

National Institute of Standards and Technology

Arati Prabhakar. Director 


\section{Reports on Computer Systems Technology}

The National Institute of Standards and Technology (NIST) has a unique responsibility for computer systems technology within the Federal government. NIST's Computer Systems Laboratory (CSL) develops standards and guidelines, provides technical assistance, and conducts research for computers and related telecommunications systems to achieve more effective utilization of Federal information technology resources. CSL's responsibilities include development of technical, management, physical, and administrative standards and guidelines for the cost-effective security and privacy of sensitive unclassified information processed in Federal computers. CSL assists agencies in developing security plans and in improving computer security awareness training. This Special Publication 500 series reports CSL research and guidelines to Federal agencies as well as to organizations in industry, government, and academia.

National Institute of Standards and Technology Special Publication 500-226 Natl. Inst. Stand. Technol. Spec. Publ. 500-226, 15 pages (Feb. 1995) CODEN: NSPUE2

\section{U.S. GOVERNMENT PRINTING OFFICE WASHINGTON: 1995}


Table of Contents

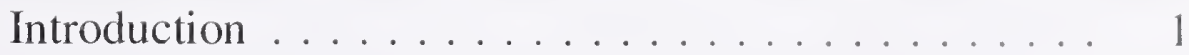

Background .................

About this Report .............. 3

Monitoring Accounting Systems in the Past ..... . 4

Need for Change ................. 5

Self Monitoring Allows Management to be Proactive . 6

Considerations for Implementation of the Self

Monitoring Service . . . . . . . . . . . . 8

Conclusions ..................... 10

References ...................... 11 
Introduction

Background
On January 8, 1993 Charles A. Bowsher, Comptroller General of the United States, testified before the Committee on Governmental Affairs of the United States Senate. He discussed the high-risk series of reports issued by the General Accounting Office (GAO). This series of reports focused on the Federal Government's efforts to identify and correct problems in 17 areas that the GAO identified as especially vulnerable to waste, fraud, abuse, and mismanagement. When the GAO started its high-risk program in November 1989 , they reported that it was evident that "the government did not have the internal control and accounting systems necessary to effectively operate many of its programs and safeguard its assets."

In November 1990 Congress enacted the "Chief Financial Officers (CFO) Act of 1990."

Three findings listed in the Act (as amended) are as follows:

- "Billions of dollars are lost each year through fraud, waste, abuse, and mismanagement among the hundreds of programs in the Federal Government."

- "These losses could be significantly decreased by improved management, including improved central coordination of internal controls and financial accounting."

- "The Federal Government is in great need of fundamental reform in financial management requirements and practices as financial management systems are obsolete and inefficient, and do not provide complete, consistent, reliable, and timely information."

One purpose for the Act listed in the document is... "Provide for improvement, in each agency of the Federal Government, of systems of accounting, financial management, and internal controls to assure the issuance of reliable financial information and to deter fraud. waste, and abuse of Government resources." 
The Act establishes the following:

- a Deputy Director for Management within OMB -- shall be the chief official responsible for financial management in the United States Government;

줌 an Office of Federal Financial Management in OMB;

- nothing in the Act shall be construed to interfere with the exercise of the functions, duties, and responsibilities of the Department of the Treasury, as in effect immediately before the enactment of this Act;

agency Chief Financial Officers;

- need for OMB to submit a government wide 5-year financial management plan;

- need for Financial Statements by agencies submitted to OMB; and

- need for Financial Statements to be audited in accordance with applicable generally accepted government auditing standards.

In 1990 the Federal Accounting Standards Advisory Board (FASAB) was created. The mission of the FASAB is to recommend accounting standards for the federal government. The board must consider the financial and budgetary information needs of congressional oversight groups, executive agencies, and the needs of other users of Federal financial information.

In April 1994 the "Core Financial System Requirements" document, from the Joint Financial Management Improvement Program, was updated to reflect the passage of the Chief Financial Officers Act of 1990; the creation of the Federal Accounting Standards Advisory Board; the experiences of the departments and agencies in using the original document; and the views of the CFO Council's Financial Systems Committee, the President's Council on Integrity and Efficiency, and others interested in improving financial systems in the federal government. The "Core Financial System Requirements" document establishes standard requirements for the backbone applications of an agency's integrated financial management system. 
Another current initiative of the Treasury Department, the Treasury Financial Management Service (FMS) consists of the following components:

- The U. S. Standard General Ledger

- The Federal Agencies Centralized Trial Balance System

- Credit Reform

In congressional testimony Treasury's Financial Management Service said... "With the increasing implementation of the U. S. Standard General Ledger (SGL) in the agencies, a much improved system becomes possible. 'Standard' is the key word. With the SGL, agencies across government identify certain accounts in the same way. Because of this standardization, it is possible to retrieve the actual account balances directly out of the agencies' accounting systems, thus eliminating the need for manually compiled reports. Because of this standardization, agencies are able to write computer programs which more fully automate the transmission of financial data to FMS."

About this Report

This report focuses on one of the two major aspects discussed above, the need for more dependable accounting and financial systems. The need for more "Standard" accounting systems across government will be addressed in future work on "Open Accounting Systems." This report recommends a service for use by management in performing self audits of financial systems. Tools used in the past by Electronic Data Processing (EDP) auditors to audit accounting systems are examined, and the similarities between these tools and the service recommended in this report can be observed. The use of this service is then described as it would be used within the accounting system. How the service can provide more internal control and financial information usually obtained from analysis performed by financial consultants is explained. 
Monitoring Accounting Systems in the Past
Historically "monitoring" of accounting systems has been in the form of audits conducted by internal auditors such as those from the Office of the Inspector General, or from outside auditors such as those from the General Accounting Office. Generalized Audit Software, and the Integrated Test Facility are primary tools used in performing audits on computerized accounting systems. This computer software typically can be installed on the system under audit, and allows the auditor to extract and analyze data from the financial records within that system. Some of the functions in generalized audit software allow auditors to perform the following:

- data file analysis, inquiry, and extraction;

- statistical sampling, file summarization, footing and recomputation;

- comparing, joining and merging files; and

aging Accounts Receivable, gap and duplicate record detection.

The Integrated Test Facility is used for the test of:

- edit checking and verification criteria;

- database updates and security features such as transaction rollbacks

- computer generated transactions; and output.

This software has become more powerful and easier to use over the past few years, and now crosses all computing platforms from mainframe to minicomputers to microcomputers. 
Need for Change
It can be easily determined that the methods of the past are not totally adequate. The audit function has always been, and will remain, an important function. It has always been necessary for independent verification and certification of financial records and this will not change in the future. However, it is often not possible to allow financial systems to go unaudited for any given length of time and then expect to be able to perform an audit to determine the areas and extent of problems. Even if this were possible, using only this kind of reactive auditing may not be efficient. The ability to constantly monitor (or audit) the system is needed to establish good financial integrity with our systems today. With computer technology as it is today, this method is practical. 
Self Monitoring Allows

Management to be Proactive
Management should not need auditors to tell them where problems exist. Management should have the tools and ability to find and correct problems as they occur. New accounting systems can provide ways to prevent errors from occurring. One method is to have data verification and edit-checking occur as the data are entered. Some well know edit-checks are:

mandatory fields - insures that vital information is entered in the record;

- range - checks to see that data input to a certain field fits within predefined limits;

- list - limits input to a list of pre-defined literals; and

anique - prevents the entering of two records with the same information in the key field.

In other words, reasonable edit checks and limits are established as the system is implemented. Data are compared to these checks and limits as they are entered. If the data fail the tests, the user must take the appropriate action to correct the problem. These tests greatly improve the quality of information in a financial information system. Edit-checking and data verification as described above are important and are used as data are entered into the system. They operate as a mechanism to decide if the data entered should be allowed into the system. If the data are not acceptable, they are rejected and need to be entered again. This mechanism should be considered to be the first level of self monitoring in a good financial system. Documentation should be available in a "Self Monitoring" section of the manuals and should describe in detail the tests that are performed on data being entered into the system. These edit-checks and their documentation should be a part of the Self Monitoring Service. This however is only the first part of that service. Next we must verify data involved in multiple transactions such as incurring and paying a liability. Also we must verify transactions that are within an acceptable range but which still should cause management to take a second look after they are in the system. One example is the need to review valid but high dollar transactions. 
These capabilities should be included in the Self Monitoring Service as a set of reports generated by queries to the data in the system.

These reports should give the manager some of the functionality that has been used by auditors to analyze the data in the system. The service should also include those tools auditors use such as Generalized Audit Software and the Integrated Test Facility. These kinds of capabilities could and should be included in accounting systems allowing management to perform the functions and tests described previously on page 4. Management could then more easily perform financial analysis on the data from their accounting systems and they would also have the ability to find discrepancies in accounts and transactions as they occur.

The Self Monitoring Service should include expert system functionality that allows for an information store of applicable rules, regulations, accounting policy and law to be compared to transactions. This expert system functionality could be provided with or without the use of an actual expert system. The store of rules, regulations, policy, and law will be used for both edit-checks and reports to management on discrepancies found in the records. The store could also contain information regarding managements goals. The Self Monitoring Service could then test and report to management the level of success with which these goals are being met. The figure below is a flowchart of how systems are currently audited/monitored and how they would be audited/monitored with the Self Monitoring Service in place.

The unshaded blocks represent the use of Generalized Audit Software with an accounting system. The shaded areas show the Self Monitoring Service Added.

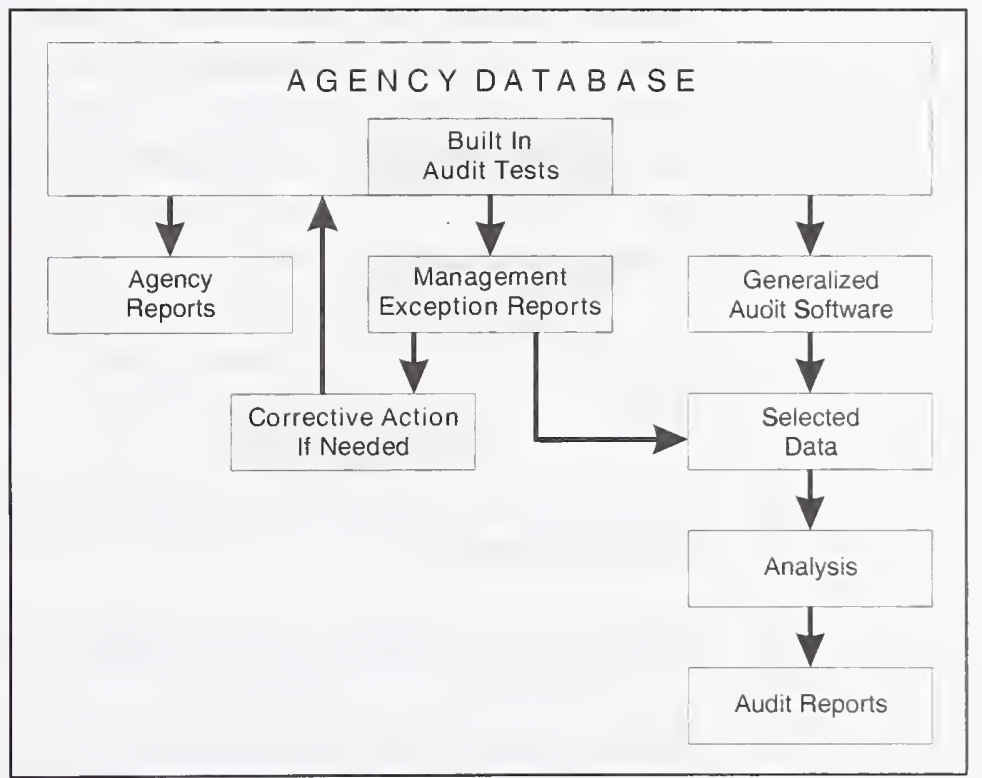


Considerations for

Implementation of the Self Monitoring Service

The Self Monitoring Service will contain a set of edit-checking and data verification functions and a set of reports based on queries made of the financial records. If the financial system is built on top of a relational database, designing these edit-checks and reports from a computer technology standpoint is simple. In any case these capabilities are technically possible. A more vexing question is where and how to implement the edit-checks and who should develop the reports for the Self Monitoring Service. The answer to this question will probably be different in each situation. In an organization that is made up of very uniform divisions, the implementation can probably be done by the developer of the financial system or at a central point in the organization. In a very diverse organization, implementation will probably be needed for each division. In most cases there will likely be a combination of these two methods. There are some areas such as travel where similarities exist in how organizations do things. This would allow a large portion of the Self Monitoring Service to be developed for an entire organization. Some minor additions or changes may be needed in some divisions or areas within the organization. These changes will most likely be more effective if they are developed with the help of the division that will use them. In all cases the help of an audit organization is essential. In the case of the federal government the Office of the Inspector General is probably a good audit organization to have involved. This involvement will assure that the set of tools in the Self Monitoring Service is complete and relevant.

The Self Monitoring Service might include the following set of edit checks or queries to the financial records:

- Prevent duplicate or overpayment for goods or services

- Prevent duplicate payments or over payments for travel

- Prevent a payment from being made to a male patient for prenatal care

- Prevent a transaction for a dollar amount that is higher than an authorized amount

- Report payments that are not made in a timely manner

- Report payments that are legal but are for a high dollar value (These may be correct, but management might want to review them) 
- Assure that benefit payments are not paid for a longer period of time than legal

- Identify all employees who received an advance of $\$ 1,000$ or more

- Identify all employees with travel claims that have been outstanding for longer than a given period

- Prevent the payment of transportation cost that exceeds the transportation cost authorized

- Identify those instances in which transportation cost claimed exceeds the transportation cost authorized

- Identify those instances where travel was completed, an advance was drawn, and the agency reimbursed the individual between specific amounts such as \$200 and \$500

- Identify all employees who took longer than 10 days to file their claims after completing their travel

- Verify the interest rate for a loan during a designated period

- Verify the discount rate for a specific quantity ordered.

Travel is an area where most organizations and parts of organizations tend to have very similar operating methods. Still it is not clear that the dollar ranges in the above example would apply to all parts of an organization. For instance, some parts of the organization might have reason to travel internationally. In this case, the dollar amounts would be expected to be higher than a part of the organization that never has the need for international travel. This is an example of where changes would be needed at various parts of the organization. 
There is concern from many levels of government regarding the need for more dependable accounting and financial systems in use within the Federal Government today. Clearly, current systems and methods of monitoring these systems are not working well. It is important to build into financial systems as many methods as possible to monitor the transactions of the systems; to have methods that determine the validity of data before they are entered into the system; and for management to be able to take a second look at particularly sensitive data after they are in the system. It is also important to build other audit tools such as Generalized Audit Software and the Integrated Test Facility into today's financial systems. Finally, it is important to include expert system functionality such as providing management reports that indicate how the data in the system compare with rules, regulations, laws and goals of the organization. Today's computer technology makes this possible. Implementors of new accounting systems should include a set of tools that prevents obviously incorrect data from being entered into the system, and allows management to review data that are determined to be sensitive to the organization. These tools should be well documented and presented in a central place within the system. This group of tools can be thought of and described to audit organizations as a Self Monitoring Service. Audit organizations base the decision of how complete an audit is needed for a system in part on the internal control included in the system. The Self Monitoring Service, if well thought out and well documented in conjunction with the audit organization, should serve to lower the audit work and the audit cost incurred by the organization in producing audited financial statements for the organization. 
References

1. Charles A. Bowsher, Comptroller General of the United States - "Government Management - Report on 17 High-

Risk Areas," Testimony Before the Committee on

Governmental Affairs, United States Senate, January 8, 1993.

2. One Hundred First Congress of the United States of America

- "Chief Financial Officers Act of 1990," January 23, 1990 (amended 1994).

3. Joint Financial Management Improvement Program - "Core Financial System Requirements," January 1988 and Revised April 1994.

4. John W. Lainhart, IV and Barry R. Snyder - "A

Simultaneous-Parallel Approach To Testing Computerized Systems," GAO Review, Summer 1977.

5. United States General Accounting Office - "Assessing the Reliability of Computer-Processed Data," GAO/OP-8.1.3, September 1990. 


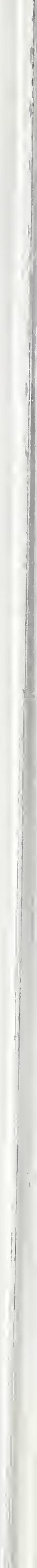




\title{
ANNOUNCEMENT OF NEW PUBLICATIONS ON COMPUTER SYSTEMS TECHNOLOGY
}

\author{
Superintendent of Documents \\ Government Printing Office \\ Washington, DC 20402
}

\section{Dear Sir:}

Please add my name to the announcement list of new publications to be issued in the series: National Institute of Standards and Technology Special Publication 500-.

Name

Company

Address

City State

Zip Code

(Notification key N-503) 


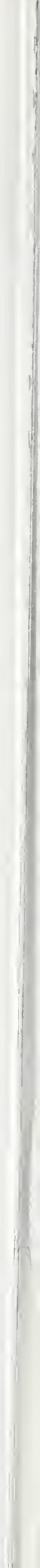






\section{NTSTTechnical Publications}

\section{Periodical}

Journal of Research of the National Institute of Standards and Technology—Reports NIST research and development in those disciplines of the physical and engineering sciences in which the Institute is active. These include physics, chemistry, engineering, mathematics, and computer sciences. Papers cover a broad range of subjects, with major emphasis on measurement methodology and the basic technology underlying standardization. Also included from time to time are survey articles on topics closely related to the Institute's technical and scientific programs. Issued six times a year.

\section{Nonperiodicals}

Monographs-Major contributions to the technical literature on various subjects related to the Institute's scientific and technical activities.

Handbooks - Recommended codes of engineering and industrial practice (including safety codes) developed in cooperation with interested industries, professional organizations, and regulatory bodies.

Special Publications-Include proceedings of conferences sponsored by NIST, NIST annual reports, and other special publications appropriate to this grouping such as wall charts, pocket cards, and bibliographies.

National Standard Reference Data Series-Provides quantitative data on the physical and chemical properties of materials, compiled from the world's literature and critically evaluated. Developed under a worldwide program coordinated by NIST under the authority of the National Standard Data Act (Public Law 90-396). NOTE: The Journal of Physical and Chemical Reference Data (JPCRD) is published bimonthly for NIST by the American Chemical Society (ACS) and the American Institute of Physics (AIP). Subscriptions, reprints, and supplements are available from ACS, 1155 Sixteenth St., NW, Washington, DC 20056.

Building Science Series-Disseminates technical information developed at the Institute on building materials, components, systems, and whole structures. The series presents research results, test methods, and performance criteria related to the structural and environmental functions and the durability and safety characteristics of building elements and systems.

Technical Notes-Studies or reports which are complete in themselves but restrictive in their treatment of a subject. Analogous to monographs but not so comprehensive in scope or definitive in treatment of the subject area. Often serve as a vehicle for final reports of work performed at NIST under the sponsorship of other government agencies.

Voluntary Product Standards-Developed under procedures published by the Department of Commerce in Part 10. Title 15, of the Code of Federal Regulations. The standards establish nationally recognized requirements for products, and provide all concerned interests with a basis for common understanding of the characteristics of the products. NIST administers this program in support of the efforts of private-sector standardizing organizations.

Order the following NIST publications_FIPS and NISTIRs-from the National Technical Information Service, Springfield, VA 22161.

Federal Information Processing Standards Publications (FIPS PUB)-Publications in this series collectively constitute the Federal Information Processing Standards Register. The Register serves as the official source of information in the Federal Government regarding standards issued by NIST pursuant to the Federal Property and Administrative Services Act of 1949 as amended, Public Law 89-306 (79 Stat. 1127), and as implemented by Executive Order 11717 (38 FR 12315, dated May 11, 1973) and Part 6 of Title 15 CFR (Code of Federal Regulations).

NIST Interagency Reports (NISTIR) - A special series of interim or final reports on work performed by NIST for outside sponsors (both government and nongovernment). In general, initial distribution is handled by the sponsor; public distribution is by the National Technical Information Service, Springfield. VA 22161. in paper copy or microfiche form. 
